\title{
EDUCATIVE HYBRID INTERVENTION AS A STRATEGY FOR REINTEGRATION TO THE CLINICAL COURSES OF UNDERGRADUATE STUDENTS DURING COVID-19 PANDEMIC
}

\author{
Valdes-Garcia $\mathrm{JE}^{1 *}$, Dominguez-Cherit $\mathrm{G}^{1,2}$, Luna-Ceron $\mathrm{EL}^{1,2}$, \\ Pherez-Farah $\mathrm{A}^{1,2}$, Muzquiz-Aguirre $\mathrm{S}^{1,2}$, Mancilla-Ortega $\mathrm{JP}^{1,2}$, \\ Vichi-Lima $\mathrm{LJ}^{1,2}$, Montejo-Romo $\mathrm{SJ}^{2,3}$, Bonilla-Hernández $\mathrm{R}^{2,4}$, \\ Arizpe-Vilana $\mathrm{D}^{2,5}$, Jimenez-Becerril $\mathrm{K}^{1}$, Rios-Barrientos $\mathrm{E}^{1}$, \\ Garibay-Huarte $\mathrm{T}^{1}$, Jean-Silver ER ${ }^{1}$, Zaragoza-Guerra V, Diaz- \\ Elizondo JA ${ }^{1}$, Rivero-Sigarroa $\mathrm{E}^{1,2}$ and Zerón-Gutiérrez $\mathrm{L}^{1}$ \\ ${ }^{1}$ Escuela de Medicina y Ciencias de la Salud, Tecnológico de Monterrey, Mexico \\ ${ }^{2}$ Instituto Nacional de Ciencias Médicas y Nutrición "Salvador Zubirán”, Mexico \\ ${ }^{3}$ Facultad Mexicana de Medicina, Universidad La Salle, Mexico \\ ${ }^{4}$ Escuela Nacional de Medicina y Homeopatía, Instituto Politécnico Nacional, Mexico \\ ${ }^{5}$ Facultad de Medicina, Universidad Popular Autónoma del Estado de Puebla, Mexico
}

\begin{abstract}
The SARS-COV-2, pandemic generated the need to modify the current clinical educational model with the challenge of promoting safety as well as the continuity of clinical education through the use of virtual platforms. Since clinical training in hospital institutions cannot be substituted, a strategic training plan was developed to guarantee protection, safety, and academic continuity for students upon their return to clinical clerkships. The objective of this project was to develop and evaluate the impact of a hybrid massive training plan as an educative strategy to give the theoretical and practical knowledge required for the safe return of undergraduate students to their respective clinical activities in the context of this pandemic. An academic program was designed through a massive hybrid strategy to train 616 undergraduate students studying clinical cycles by presential, virtual, synchronous, and asynchronous activities. To know the impact of the program, a pre-experimental study with pre-test and post-test was carried out to evaluate the acquisition of the important knowledge and skills of the program. A significant difference was found between the means of the initial and final evaluations ( $\mathrm{p}$ $<0.001$ ), as well as a high impact of the intervention (d 1.6). Significant improvements in the areas of COVID-19 initial management $(\mathrm{p}<0.001)$ and personal protective equipment use $(\mathrm{p}<0.001)$ were seen in the post-test when comparing to the initial evaluation. A quantitative and qualitative analysis of the satisfaction survey was carried out, finding positive results on the course design, quality of didactic resources, and instructors' performance massive hybrid training is an effective strategy to facilitate the reintegration of undergraduate students to their face-to-face clinical rotations.
\end{abstract}

Keywords: COVID-19 Hybrid education, Clinical clerkships, Training, Distance learning, Educational model 


\section{Introduction}

The COVID-19 pandemic, declared by the WHO in March 2020, has generated an unprecedented impact on the education sector, affecting nearly 1.5 billion students worldwide and more than 37 million in Mexico.(Gishen F, 2020) Particularly in medical education, the Mexican Association of Faculties and Schools of Medicine (AMFEM) and the Association of American Medical Colleges (AAMC) recommended the temporary suspension of clinical activities given that in addition to compromising the health of undergraduate students, they did not have the necessary skills to face the pandemic.(Gishen F, 2020; Medicina.; Prescott, 2020; UNESCO, 2020) The National School of Medicine and Health Sciences (EMCS) of the Tecnológico de Monterrey withdrew the students from hospital and outpatient areas of the degrees of Nutrition and Comprehensive Well-being (LNB), Surgeon Odontologist (MO), and Surgeon (MC) as of March 17, being the first Mexican institution to take this measure.(Medicina., 2020; Monterrey Institute of Technology, 2020; Valdez-Garcia JE, 2020; S. Wiener, 2020)

Various institutions have implemented strategies to ensure compliance with the objectives of their programs, migrating them from a face-to-face mode to a virtual one. Several observational studies have shown the usefulness of the latter to maintain learning processes; However, student satisfaction rates have been suboptimal.(Al-Balas et al., 2020; Sandhaus, Kushnir, \& Ashkenazi, 2020) In the United Kingdom it was evidenced that virtual education limits student participation and that online classes are less effective during the period of clinical rotations, highlighting the importance of contact with patients, which is why the hybrid model has emerged as an alternative. (Mian \& Khan, 2020; Rosales-Gracia S, 2008; Rose, 2020; Roskvist, Eggleton, \& Goodyear-Smith, 2020; S Wiener, 2020)

According to a study carried out at the University of West Chester, $64 \%$ of the students felt more involved with the course content in the hybrid format and $90 \%$ found it convenient.(Rosales-Gracia S, 2008) Given its effectiveness in promoting greater learning, some of the best universities in the world, such as the Imperial College of London, the Massachusetts Institute of Technology, and the University of Maryland, have incorporated this model into their educational offerings. Under the current context, the main challenge is to define how much learning can be undertaken online and how much clinical exposure is still needed.(Fredin, 2017; Gishen F, 2020; Roskvist et al., 2020)

Given the importance of reintegration into the clinical environment within a "new normal", universities must design a strategic training plan that guarantees the safety, academic continuity, and emotional support of students, who face educational uncertainty and fear derived from the disease.(AMA, 2020; Gallagher \& Schleyer, 2020; Hilburg, Patel, Ambruso, Biewald, \& Farouk, 2020; Valdez-García JE, 2020) The AAMC published a guide for medical student contact with patients during the pandemic, emphasizing three points: information on COVID-19, proper use and availability of Personal Protective Equipment (PPE), and dynamics of the hospital service, taking into account the systematization of actions and standards necessary to optimize care.(Valdez-Garcia JE, 2020; Whelan A, 2020)

At the Tecnológico de Monterrey, after 3 months of withdrawal of undergraduate students from clinical courses, the possibility of their reincorporation for the month of July was raised, so a hybrid educational strategy was designed to provide the knowledge and skills fundamental to face the COVID-19 pandemic. The objective of this study was to evaluate the theoretical knowledge, skills, 
and experiences acquired by students in the health area thanks to said training program to achieve an adequate face-to-face reintegration to their respective clinical fields.

\section{Material and methods}

An educational intervention based on a hybrid strategy was designed with 3 general objectives: medical training in COVID-19, proper use of PPE, and general and hospital biosecurity measures. (Figure 1) To register, the students had to accredit a series of prerequisites that consisted of taking general courses on COVID-19 and biosafety. Once passed, they were given access to the course that consisted of a theoretical seminar and a practical workshop on the use of PPE through the Canvas platform (Instructure Inc, Utah, USA), where the school control and the initial and final evaluations were carried out, in addition to serving as a repository for the lectures given.

The theoretical seminar was designed in a synchronous virtual format and lasted 20 hours, taught over 5 days by professors from EMCS and the National Institutes of Health, through platforms such as Zoom (Zoom video communication Inc, California, USA) and Microsoft Teams (Microsoft, Washington, USA). For its part, the workshop on the use of PPE was carried out in simulation spaces and consisted of an asynchronous phase through a theoretical instructional video and a practical faceto-face phase of 2 hours duration.

A demographic and exploratory analysis was carried out using descriptive statistics. To verify the normality of the distribution of the variables, corresponding to the scores in the initial and final evaluations, the Kolmogorov-Smirnov test was used. To compare the means between these variables, the Wilcoxon $\mathrm{W}$ test was performed for non-parametric distribution. To evaluate the size of the impact of this intervention, Cohen's D test was performed. To analyze the change in the proportions of questions answered correctly in the initial and final evaluation, a two-sample z-test of proportions was used. All statistical tests were carried out using StataCorp Stata MP software (Version 14.0, College Station, TX, USA). The results of these analyzes were presented graphically using GraphPad Prism 8 software (Version 8.0, San Diego, CA, USA). The figures were made by using the Biorender platform (Biorender Company, 2017, USA). The qualitative analysis of the feedback from the trained group was done using the MaxQDA software (Version 2020, Berlin, Germany). The ethical protocols required by the research center for the recruitment and evaluation of study subjects were followed, and they were duly informed about the purposes of this study and decided to participate voluntarily. 


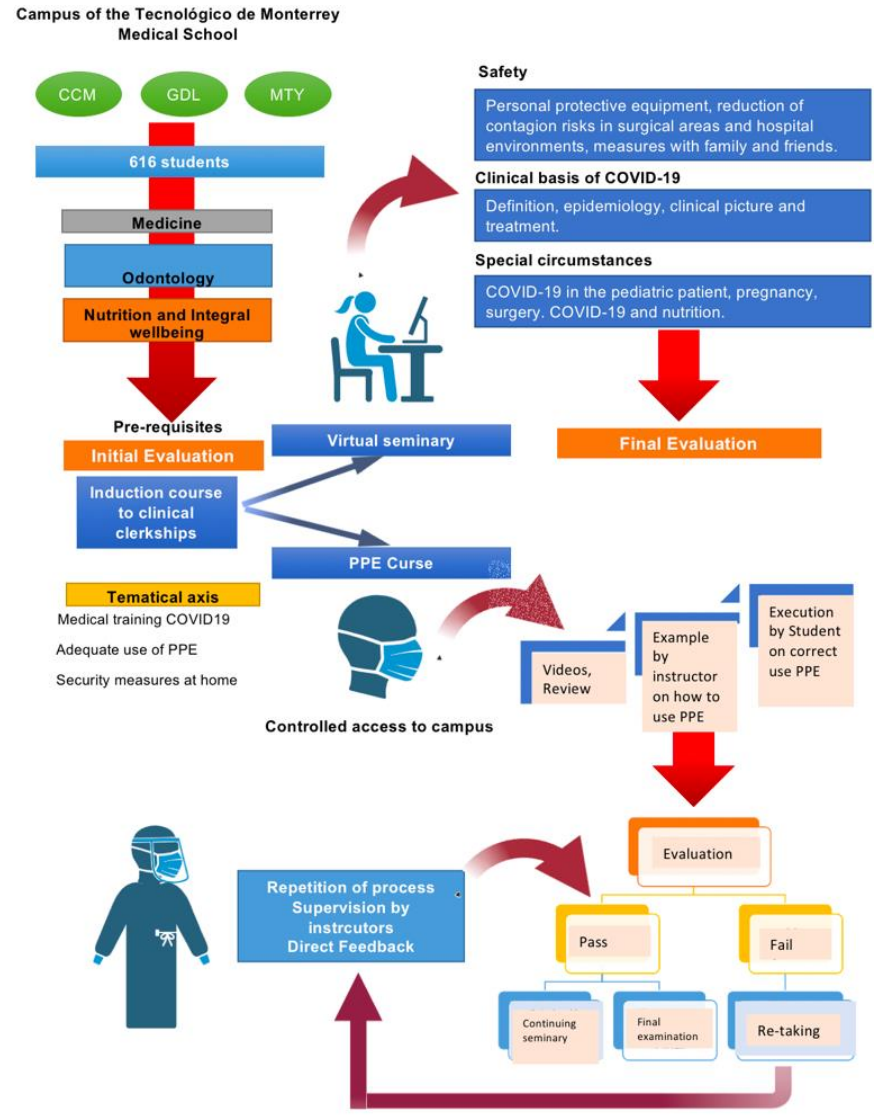

Figure 1: Design of the hybrid educational strategy aimed at undergraduate students in clinical courses.

The logistical mechanisms used to carry out the face-to-face workshop on personal protective equipment (PPE) and the thematic axes of the virtual theoretical seminar are distinguished. CCM: Mexico City Campus; GDL: Guadalajara Campus; MTY: Monterrey Campus.

\section{Results}

During the intervention period, a total of 616 students were trained, of which $60.47 \%$ were from Campus Monterrey, $27.85 \%$ from Campus Ciudad de México, and $11.68 \%$ from Campus Guadalajara. Almost $90 \%$ corresponded to the MC career, followed by LNB with $8 \%$ and MO with less than $2 \%$. Only $28 \%$ were in the sixth year, as the duration of the LNB and MO careers is shorter than that of MC. As additional data, only $6.5 \%$ of the students reported having some risk factor for the development of severe COVID-19. (Table 1)

Table 1: Demographic analysis of trained population

\begin{tabular}{lll}
\hline Total students & $100 \%$ & 616 \\
\hline Campus & & \\
\hline Monterrey & $60.47 \%$ & 372 \\
\hline Mexico City & $27.85 \%$ & 172 \\
\hline Guadalajara & $11.68 \%$ & 72 \\
\hline Year & & \\
\hline
\end{tabular}




\begin{tabular}{lll}
\hline Fifth year & $37.17 \%$ & 229 \\
\hline Sixth year & $62.82 \%$ & 389 \\
\hline Degree & & \\
\hline Medical Surgeon (\%) & $89.3 \%$ & 550 \\
\hline $\begin{array}{l}\text { Nutrition and Integral wellbeing } \\
(\%)\end{array}$ & $8 \%$ & 49 \\
\hline Odontology (\%) & $1.8 \%$ & 11 \\
\hline Risk factors for COVID-19 & & \\
\hline No (\%) & $93.5 \%$ & 576 \\
\hline Yes $(\%)$ & $6.5 \%$ & 40 \\
\hline
\end{tabular}

570 students participated in the initial evaluation, with a mean of $77 \%$ correct answers (SD \pm 14.97 ). (Figure 2A) The questions explored 4 main areas: handwashing technique and times, classification of patients with respiratory disease, initial management of the patient with COVID-19, and management of PPE. It was observed that in the first area there was adequate mastery of the subject, with $92 \%$ and $97 \%$ of correct answers for technique and times for handwashing, respectively. (Figures 2B-C) Regarding the classification of patients with respiratory disease, a lesser domain of the subject began to be observed, finding only $73 \%$ of correct answers. (Figure 2D) Finally, in the last two areas, the domain was lower, with $41 \%$ and $44 \%$ incorrect answers, respectively. (Figures 2E-F)

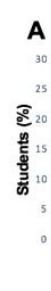

D

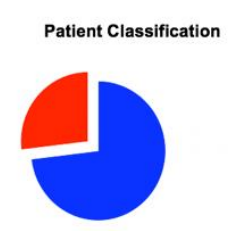

(a)
B

Handwashing technique

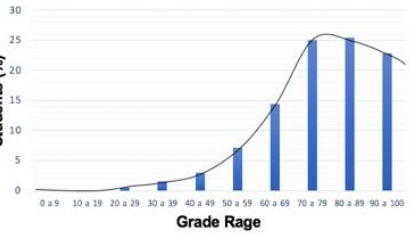

(20)

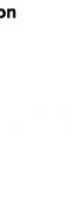

$\mathbf{E}$

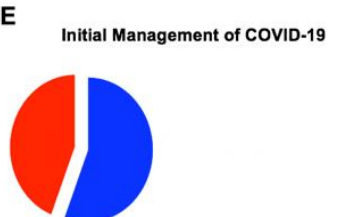

C

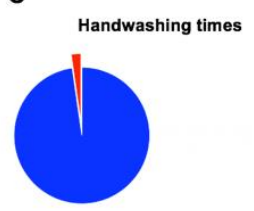

$\mathbf{F}$

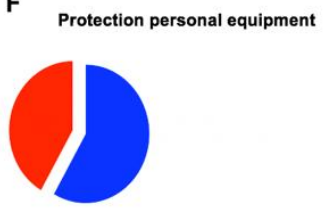

Figure 2: Results of the diagnostic evaluation of the clinical science induction training program. (A) Distribution of grades in the initial evaluation showing a mean of $77 \%$ of correct answers $(S D \pm 14.97), n=$ 570. $(B-F)$ Exploration of in-hospital skills management in a health emergency situation. (B) Mastery of the hand washing technique $(C)$ Mastery of the concept of the 5 times of hand washing. $(D)$ Identification and classification of patients with respiratory disease $(E)$ Mastery of the approach and initial management of the patient with suspected COVID-19. (F) Proper handling of personal protective equipment. $N=570$. Adequate domain is depicted in blue and inadequate domain in red.

Due to limitations in the design of the evaluations, it was not possible to perform descriptive statistics by career. 616 students participated in the final evaluation, with a mean of $96 \%$ correct responses (SD $\pm 7.32)$, showing a significant difference concerning the initial mean $(\mathrm{p}<0.001)$ and observing that the impact of the evaluation was high (d 1.6) (Figures 4A and 4B). The questions explored the same areas as in the initial assessment, but an additional one was added: SARS-CoV-2 transmission mechanisms, where a 99\% dominance was observed (Figure 3C). In the rest of the areas, a significant improvement was found, finding a domain greater than $90 \%$ in all except in the classification of the patient with respiratory disease, where $15 \%$ had an inadequate domain, representing an area of opportunity. (Figures 3B and 3D-F) A significant change was observed between the proportions of students who 
had adequate mastery in the final evaluation compared to the initial one in the areas of initial management of patients with COVID-19 ( $\mathrm{p}<0.001)$ and management of the EPP ( $\mathrm{p}<0.001)$, finding an increase greater than $31 \%$ and $37 \%$, respectively. (Figures 4C-D) Therefore, it can be seen that although PPE management was the area with the worst performance initially, it was also the one that saw the greatest improvement.

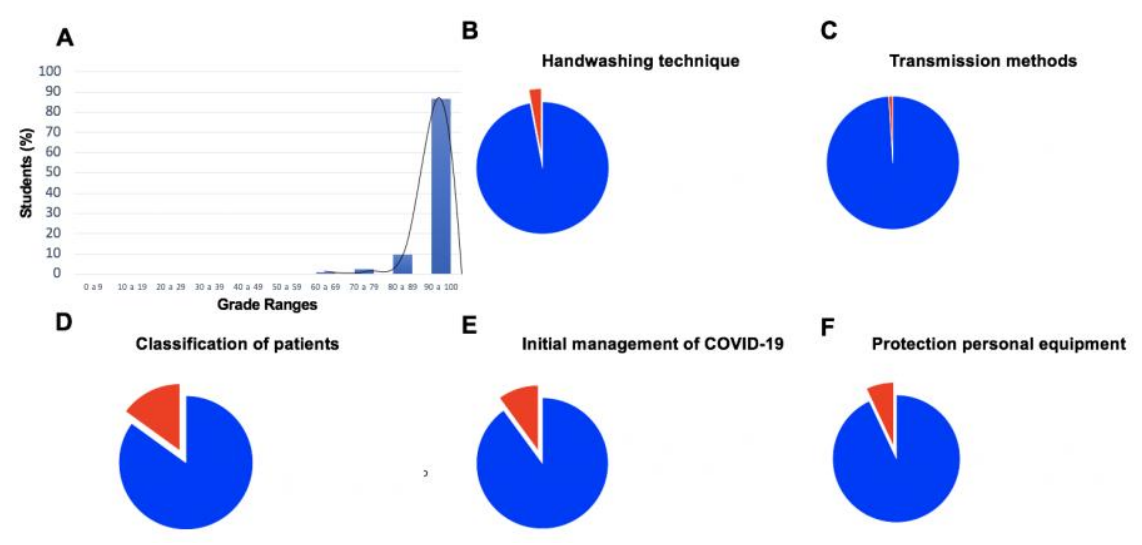

Figure 3: Results of the final evaluation of the clinical science induction training program. (A) Distribution of grades in the initial evaluation showing a mean of $96 \%$ correct answers $(S D \pm 7.32), n=616 .(B-F)$

Exploration of in-hospital skills management in a health emergency situation (B) Mastery of the hand washing technique (C) Mastery of the concept of the transmission mechanisms of SARS-CoV-2. (D) Identification and classification of patients with respiratory disease (E) Mastery of the approach and initial management of the patient with suspected COVID-19. (F) Proper handling of personal protective equipment. $N=616$. Adequate domain is depicted in blue and inadequate domain in red.

A

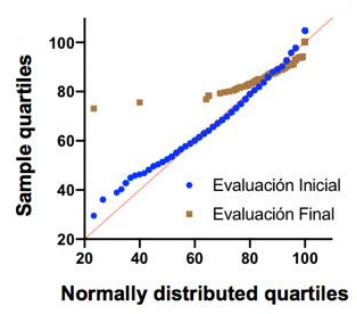

B

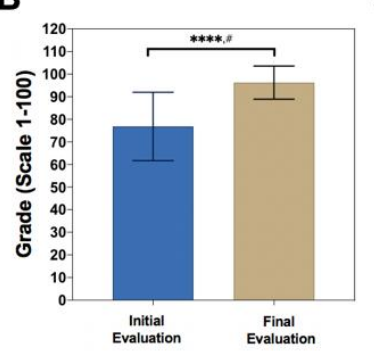

C

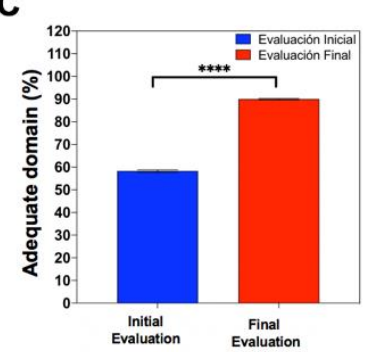

D

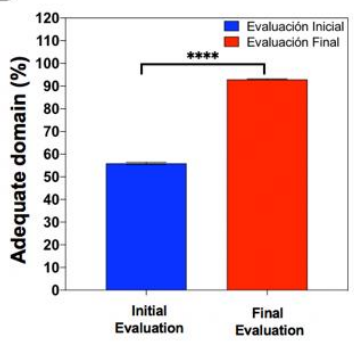

Figure 4: Global results of the impact of the training program for induction to clinical sciences. (A) $Q-Q$ graph showing the differences between the distribution of the initial and final assessment scores compared to the

Gaussian normal distribution. It was demonstrated that there was a non-normal distribution using the

Kolmogorov-Smirnov test $(K S$ distance $=0.0188)(B)$ Comparison of the means corresponding to the initial and final evaluations with Wilcoxon's $W$. ${ }^{* * * *} p \leq 0.001$. \# Cohen's D test with a statistic of 1.66 shows a high impact of the intervention. (C) Comparison of the proportions with adequate mastery in the initial management of the patient with COVID-19 in the initial and final evaluation, $* * * * p \leq 0.001$. (D) Comparison of the proportions of adequate mastery of the technique of use of personal protective equipment in the initial and final evaluation, ${ }^{* * * *} p \leq 0.001$. The comparison of proportions was evaluated with a $z$-test for two samples. $n 1=$ $570, n 2=616$.

A satisfaction survey was carried out that was, in general terms, favorable. The following areas were evaluated: planning, content, relevance for clinical fields, quality of technological resources, PPE workshop, speaker performance, and global evaluation. Six of the areas were rated positively by more than $95 \%$ of those surveyed, with "excellent" being the qualifier most frequently used in these cases. A notable exception was in the quality of technological resources, since $10 \%$ classified them as fair and almost $4 \%$ as bad, being the only area where this adjective was used by more than $0.5 \%$ of those 
surveyed. Furthermore, unlike the rest of the areas, the most frequent rating was not "excellent", but "very good". The latter is partially explained by the speed with which the platform had to be designed as it was an emergency, but it represents an area of opportunity for future interventions. (Figures 5AG)
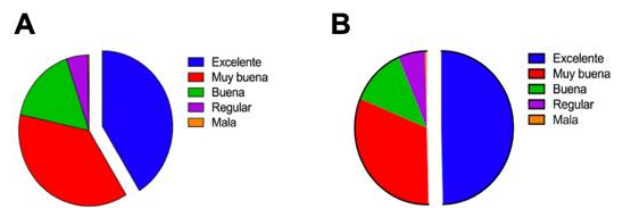

C
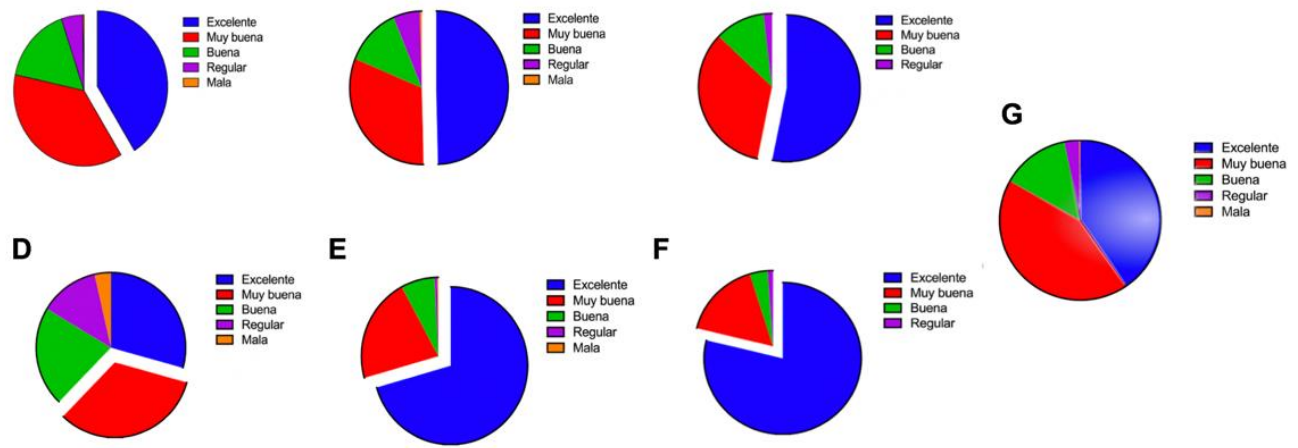

Figure 5: Results corresponding to the personal satisfaction survey. (A) Overall impression of the quality of the course planning. (B) Overall impression of the quality of the course content. (C) Opinion about the relevance of the course for its application in clinical fields. (D) Impression of the quality of technological resources. $(E)$ Overall impression of the quality of the workshop on personal protective equipment. $(F)$ General impression of the performance of the speakers. $(G)$ Overall perception of the course. $N=616$. Results are depicted following

this scale: "Excellent": Blue; "very good": Red; "Good": Green; "Regular": Purple; "Bad": Orange.

A qualitative analysis of the feedback comments was also carried out, where several positive qualifying adjectives were found among the most used words. However, a high frequency of words related to fear was also found, reflecting a potential area of intervention through psychological support. (Figures 6A-B) Finally, this analysis was also useful to detect other negative aspects that were not quantitatively observed; for example, the significant frequency of respondents whose impression was that some topics and presentations were repetitive and/or of long duration, possibly again representing the haste with which the course had to be designed. (Figure 6C)

A

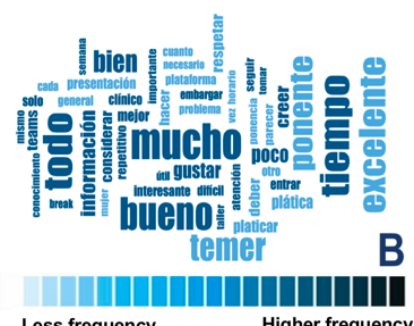

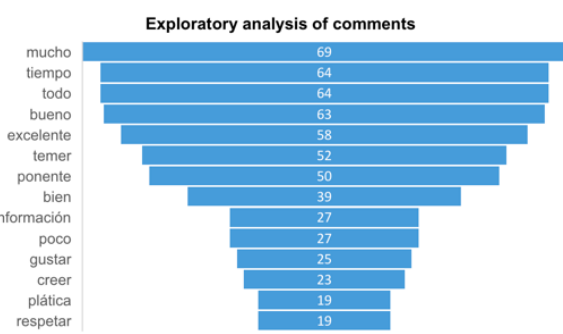

C

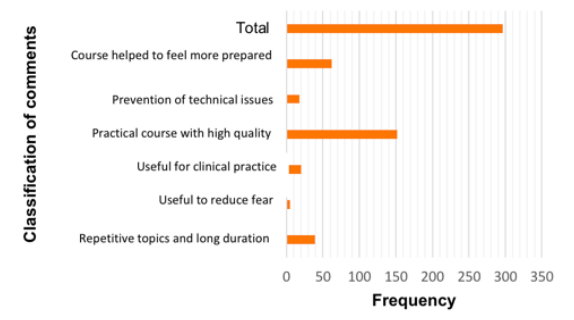

Figure 6: Qualitative analysis of the feedback comments from the trained group. (A) Word cloud scheme that shows the frequency of words used in comments, their frequencies are presented in color code and font size (see scale). (B) Frequency of the most relevant keywords in the exploratory analysis (only the 14 most frequent are presented). (C) Conceptual classification of feedback comments. $N=296$.

\section{Discussion}

To the extent of our knowledge, the development of a hybrid intervention model that would allow students in the health area to be trained to safely reintegrate into their clinical activities has not been published. Therefore, evaluating the impact of the training model described here is essential for the 
development of future interventions. The results of the initial evaluation demonstrate that the students had an acceptable mastery in various areas required for their daily clinical activities, such as the technique and moments of hand washing. These results are in contrast to that reported in other studies in which only a small percentage of them have an adequate domain in this area.(Al Kadi \& Salati, 2012) On the other hand, the results observed in other aspects such as the management of PPE were alarming, this being the area with the worst domain despite being essential for its safe clinical performance under the current context. These results showed that a face-to-face intervention was necessary to improve this particular competence.

The overall impact of this intervention turned out to be very satisfactory, as it demonstrated a substantial increase in the final averages concerning the initial ones, as well as in the domain of each one of the evaluated areas. It can also be observed that the areas where the worst performance was initially had, such as the management of PPE and the initial management of the patient with COVID19, were those that showed the greatest improvement, possibly due to the support of the face-to-face practical workshop, which addressed these aspects. Additionally, the results of the satisfaction survey, as well as the qualitative analysis of the students' comments, showed that the design and implementation of this model were acceptable. The perception of high applicability of the contents stands out, which contrasts with other interventions where one of the main drawbacks has been the complexity and lack of clinical applicability.(Capan Melser et al., 2020) Additionally, this intervention had higher rates of student acceptance compared to previously published interventions, which used a virtual model.(Al-Balas et al., 2020; Dedeilia et al., 2020)

This program also showed challenges and areas of opportunity. It was shown that the main setback was the presence of technical failures and the lack of adaptation to technological platforms by the students and the teaching team. Similarly, other virtual medical education interventions have also referred to these limitations.(Al-Balas et al., 2020; Mukhtar, Javed, Arooj, \& Sethi, 2020) Also, there was a significant perception that the sessions were of excessive duration and repetitive content, therefore, for the development of future interventions, they are required greater planning efforts and content delimitation. Possibly the development of a more specific course and with more practical activities have a greater impact on students. In the qualitative analysis of the comments, it was also interesting that the students reported a reduction in the perception of fear of contagion associated with returning to their clinical activities, which has been a problem consistently reported in other studies.(Compton, Sarraf-Yazdi, Rustandy, \& Radha Krishna, 2020; Dedeilia et al., 2020) However, this intervention did not make an evaluation aimed at the psychological response of the students to the stress generated by their reintegration to clinical activities and represents an area ofopportunity for the development of future research.

\section{Conclusions}

The hybrid model of intervention that was developed allowed students from the health area to be trained to safely reintegrate into their clinical activities. Therefore, we conclude that evaluating the impact of the training model described here is essential for the development of future interventions. 


\section{Acknowledgements}

We greatly appreciate the support received by the collaborators of the Departments of Clinical Sciences of each of the Tecnológico de Monterrey campuses, as well as the team of professors who made possible the development of the contents, distribution and dissemination of this educational intervention.

\section{References}

Al Kadi, A., \& Salati, S. A. (2012). Hand Hygiene Practices among Medical Students. Interdisciplinary perspectives on infectious diseases, 2012, 679129-679129. doi:10.1155/2012/679129

Al-Balas, M., Al-Balas, H. I., Jaber, H. M., Obeidat, K., Al-Balas, H., Aborajooh, E. A., . . Al-Balas, B. (2020). Distance learning in clinical medical education amid COVID-19 pandemic in Jordan: current situation, challenges, and perspectives. BMC Medical Education, 20(1), 341. doi:10.1186/s12909-020-02257-4

AMA. (2020). AMA guiding principles to protect learners responding to COVID-19. Retrieved from https://www.ama-assn.org/delivering-care/public-health/ama-guiding-principles-protect-learnersresponding-covid-19

Capan Melser, M., Steiner-Hofbauer, V., Lilaj, B., Agis, H., Knaus, A., \& Holzinger, A. (2020). Knowledge, application and how about competence? Qualitative assessment of multiple-choice questions for dental students. Medical education online, 25(1), 1714199-1714199. doi:10.1080/10872981.2020.1714199

Compton, S., Sarraf-Yazdi, S., Rustandy, F., \& Radha Krishna, L. K. (2020). Medical students' preference for returning to the clinical setting during the COVID-19 pandemic. Medical education, 54(10), 943-950. doi:10.1111/medu.14268

Dedeilia, A., Sotiropoulos, M. G., Hanrahan, J. G., Janga, D., Dedeilias, P., \& Sideris, M. (2020). Medical and Surgical Education Challenges and Innovations in the COVID-19 Era: A Systematic Review. In Vivo, 34(3 suppl), 1603. doi:10.21873/invivo.11950

Fredin, E. (2017). Aprendizaje híbrido: ¿el futuro de la educación superior? Retrieved from https://observatorio.tec.mx/edu-news/2017/10/13/aprendizaje-hibrido-el-futuro-de-la-educacionsuperior

Gallagher, T. H., \& Schleyer, A. M. (2020). "We Signed Up for This!" - Student and Trainee Responses to the Covid-19 Pandemic. New England Journal of Medicine, 382(25), e96. doi:10.1056/NEJMp2005234

Gishen F, B. S., Gill D. . (2020). The BMJ Opinion. Retrieved from https://blogs.bmj.com/bmj/2020/04/03/covid-19-the-impact-on-our-medical-students-will-be-farreaching/

Hilburg, R., Patel, N., Ambruso, S., Biewald, M. A., \& Farouk, S. S. (2020). Medical Education During the Coronavirus Disease-2019 Pandemic: Learning From a Distance. Advances in chronic kidney disease, 27(5), 412-417. doi:10.1053/j.ackd.2020.05.017

Medicina., A. M. d. F. y. E. d. Comunicado importante Covid-19 Retrieved from http://www.amfem.edu.mx/index.php/acerca/comunicados/206-comunicado-covid-19

Medicina., A. M. d. F. y. E. d. (2020). El papel del estudiante de medicina ante la pandemia por COVID 19: una responsabilidad compartida. Retrieved from http://www.amfem.edu.mx/index.php/acerca/comunicados

Mian, A., \& Khan, S. (2020). Medical education during pandemics: a UK perspective. BMC Medicine, 18(1), 100. doi:10.1186/s12916-020-01577-y 
Monterrey Institute of Technology, I. (2020). Comunicado oficial (12 marzo - Comunicado Coronavirus) Retrieved from https://tec.mx/sites/default/files/2020-04/Comunicado-Oficial-12-demarzo-ES-12-3-20.pdf

Mukhtar, K., Javed, K., Arooj, M., \& Sethi, A. (2020). Advantages, Limitations and Recommendations for online learning during COVID-19 pandemic era. Pakistan journal of medical sciences, 36(COVID19-S4), S27-S31. doi:10.12669/pjms.36.COVID19-S4.2785

Prescott, J. (2020). Important Guidance for Medical Students on Clinical Rotations During the Coronavirus (COVID-19) Outbreak. Retrieved from https://www.aamc.org/news-insights/pressreleases/important-guidance-medical-students-clinical-rotations-during-coronavirus-covid-19outbreak

Rosales-Gracia S, G.-L. V., Durán-Rodríguez S, Salinas-Fregoso M, Saldaña-Cedillo S. . (2008). Modalidad híbrida y presencial: Comparación de dos modalidades educativas. Revista de la Educación superior, 37(148), 23-29. .

Rose, S. (2020). Medical Student Education in the Time of COVID-19. JAMA, 323(21), 2131-2132. doi:10.1001/jama.2020.5227

Roskvist, R., Eggleton, K., \& Goodyear-Smith, F. (2020). Provision of e-learning programmes to replace undergraduate medical students' clinical general practice attachments during COVID-19 stand-down. Education for Primary Care, 31(4), 247-254. doi:10.1080/14739879.2020.1772123

Sandhaus, Y., Kushnir, T., \& Ashkenazi, S. (2020). Electronic Distance Learning of Pre-clinical Studies During the COVID-19 Pandemic: A Preliminary Study of Medical Student Responses and Potential Future Impact. Isr Med Assoc J, 22(8), 489-493. Retrieved from https://www.ncbi.nlm.nih.gov/pubmed/33236581

UNESCO. (2020). Education: From Disruption To Recovery. Retrieved from https://en.unesco.org/covid19/educationresponse

Valdez-Garcia JE, E.-R. I., Díaz JA, Cordero-Díaz M, Torres-Quintanilla A, Zeron-Gutiérrez L. (2020). Observatorio de Innovación Educativa, el rol del estudiante de medicina y ciencias de la salud ante una pandemia. Retrieved from https://observatorio.tec.mx/edu-bits-blog/rol-del-estudiante-demedicina-y-ciencias-de-la-salud-ante-una-pandemia

Valdez-García JE, L.-C. M., Jiménez MA, Díaz-Elizondo JA, Dávila-Rivas JA, Olivares-Olivares SL. (2020). Me preparo para ayudar: respuesta de escuelas de medicina y ciencias de la salud ante COVID-19. Revista investigacion en Educación Médica, 9(2), 1-11. .

Whelan A, P. J., Young G, Catanese V, McKinney R. (2020). Guidance on Medical Students' Participation in Direct In-person Patient Contact Activities Retrieved from https://www.aamc.org/system/files/2020-08/meded-August-14-Guidance-on-Medical-Students-onClinical-Rotations.pdf

Wiener, S. (2020). Back to medical school during COVID-19 Retrieved from https://www.aamc.org/news-insights/back-medical-school-during-covid-19

Wiener, S. (2020). Excited, scared, ready: Medical students head back to clerkships Retrieved from https://www.aamc.org/news-insights/excited-scared-ready-medical-students-head-back-clerkships 